\title{
O Monista: a visão de mundo do Energetismo de Ostwald
}

\section{The Monist: Ostwald's Energetics worldview}

\author{
Marcelo Raphael Rocha Bichara \\ Programa de Pós-Graduação em História das Ciências e das Técnicas e Epistemologia \\ (HCTE), Universidade Federal do Rio de Janeiro (UFRJ). \\ marcelorrbichara@gmail.com \\ orcid.org/0000-0003-4589-3124
}

\section{Carlos Benevenuto Guisard Koehler}

Programa de Pós-Graduação em História das Ciências e das Técnicas e Epistemologia (HCTE), Universidade Federal do Rio de Janeiro (UFRJ).

\section{cbgk@uol.com.br}

Resumo. Este trabalho é uma resenha atualizada de um importante, porém desconhecido, artigo de filosofia da ciência intitulado "The Monist" (1907), do químico germânico natural da Letônia: Friedrich Wilhelm Ostwald (1853 - 1932), considerado o pai da físico-química. Nele o autor argumenta a favor de sua doutrina do Energetismo, uma visão de mundo não-dualista que, segundo ele, poderia fornecer à ciência um fundamento filosófico único para todas as disciplinas, unificando não somente a física e a química, mas também as ciências biológica, social e psicológica. Adotando uma postura paradoxalmente instrumentalista e realista ao mesmo tempo, o químico-filósofo lança questões ainda abertas para a ciência do futuro.

Palavras-chave: Epistemologia. Entropia. Positivismo. Atomismo. Energetismo.

Abstract. This work is a review of an important, but generally unknown, article in philosophy of science entitled "The Monist" (1907), by the Germanic Latvian chemist: Friedrich Wilhelm Ostwald (1853 - 1932), considered the father of physic-chemistry. In this paper the author argues in favor of his doctrine of Energetics, a non-dualistic world view that could offer science a unique philosophical foundation for all disciplines, unifying not only physics and chemistry, but also biology, sociology and psychology. Adopting a paradoxically instrumentalist and realistic point of view at the same time, the philosopherchemist asks questions that are still open to science in the future

Keywords: Epistemology. Entropy. Positivism. Atomism. Energetics. 


\section{Introdução}

A despeito de sua tremenda energia e atividade em sua longa carreira, Wilhelm Ostwald é uma figura negligenciada na história da ciência. Não há sequer uma biografia decente. Entre os historiadores da química, parece existir um consenso que tende a negar a criatividade de Ostwald. (BENSAUDE-VINCENT, 2005, P. 26)

Sempre envolvido em debates polêmicos, é impreciso afirmar atualmente qual foi o fator mais relevante para o seu relativo esquecimento na história da ciência. Como aponta Letícia dos Santos Pereira (2017), aqueles com mais inclinação para a história interna da ciência hão de afirmar que foi sua obstinada recusa em relação ao crescente atomismo na física que, após a revolução quântica, tornou seu trabalho inaceitável, lhe rendendo ainda duras e épicas críticas de figuras notáveis como Boltzmann e Max Planck. Os mais adeptos à história externa da ciência podem supor que, por outro lado, talvez tenha sido o seu engajamento, político e científico, na participação da Alemanha na $1^{\text {a }}$ Guerra Mundial, o que acabou por lhe render o exílio intelectual que consistiu o final triste e isolado de sua carreira na efervescente ciência atômica do pós-guerra.

Seja como for, cinco anos antes do conflito armado eclodir, Ostwald foi agraciado com o reconhecimento máximo de sua carreira científica, recebendo o Prêmio Nobel pelo seu trabalho em química ${ }^{1}$. Dois anos antes de angariar o famoso prêmio, em seu esquecido artigo "The Monist" (1907), o químico-filósofo nos fornece de modo bastante didático as definições principais de sua filosofia da ciência, afastando-se epistemologicamente tanto dos positivistas quanto dos atomistas de sua época.

Ostwald viveu no epicentro das mudanças e descobertas científicas que
ocorreram entre os séculos XIX e XX, participando ativamente dos debates
científicos, epistemológicos e políticos de seu tempo. As biografias sobre
Ostwald nos mostram um personagem multifacetado e, até certo ponto,
contraditório. (PEREIRA, 2017)

Enquanto a maioria dos cientistas de sua época, fortemente influenciados pelo movimento positivista (do qual ele próprio é um de seus mais insólitos expoentes), tinha aversão ao termo "realidade", afirmando que a ciência positiva falava apenas de suas teorias e seus instrumentos de medida - modelos práticos, funcionais e úteis - mas nunca do real em si mesmo; Oswald (1907, p.13) admite abertamente neste artigo que é "diretamente guiado" pela "questão do real", por ele entendido como "nossa relação com o mundo (Welt)". De modo propriamente kantiano, a realidade na ciência é dita aqui de ordem fenomenológica, isto é, surge pela relação entre um observador e aquilo que o rodeia. Ostwald utiliza sempre as palavras "entendimento", "inteligência" e "conhecimento" como sinônimos da capacidade de previsão ("forsee"), apontada por ele como o objetivo máximo da ciência. Tendo por um lado o conceito de real (como

\footnotetext{
1 "em reconhecimento por seu trabalho com catálise e por suas investigações sobre os princípios gerais que governam o equilíbrio químico e as taxas de reação." Wilhelm Ostwald - Facts. NobelPrize.org. Nobel Media AB 2018. Disponível em: https://www.nobelprize.org/prizes/chemistry/1909/ostwald/facts/ Acesso: 8 Sep 2018.
} 
relação sujeito-mundo) e por outro o de conhecimento (como poder de previsão), pela combinação de ambos chegamos ao seu conceito bem definido de ciência:

\begin{abstract}
Pois toda suposição e representação científica consiste em coordenar para as variedades do domínio que se quer investigar, uma outra variedade esquemática de símbolos (de natureza matemática ou linguística), na qual as relações funcionais correspondentes podem ser expressas. (OSTWALD, 1907 , p. $24[\mathrm{TN}]^{2}$ [grifo nosso]).
\end{abstract}

De modo resumido, a ciência para ele é um modo rigoroso de usar a linguagem, combinando símbolos num sistema capaz de expressar as relações funcionais manifestas no mundo, cujos efeitos são acessíveis ao observador pela sensibilidade ou pela técnica. Se algo não produz efeito observável no mundo, nada podemos dizer sobre sua realidade. Só podemos dizer que algo existe em relação com outra coisa. Note que Ostwald não faz uso neste momento da palavra "objeto" para descrever o real, pois em sua visão a ciência não estuda propriamente os objetos, não mede as "coisas em si" (para sempre inacessíveis ao sujeito kantiano), mas sempre e somente a relação entre as coisas. É neste sentido que Ostwald vai apresentar o conceito de energia como princípio fundamental de todo conhecimento científico, pois a energia não é um objeto no sentido clássico; mas sim uma medida matemática e rigorosa de como as coisas se afetam mutuamente, ou seja, a intensidade com que elas variam umas em função das outras.

\title{
2. Do instrumentalismo positivista à ontologia do Energetismo
}

Neste ponto do artigo Ostwald faz um comentário que deixa explícito sua postura monista, ao criticar a concepção cartesiana de tomar a palavra "mundo" (welt), como composto somente dos objetos "exteriores" à mente do observador; sendo os sonhos, as visões, a memória e o pensamento ditos como "irreais", ou então como fazendo parte de um "mundo interior", transcendente ao mundo físico (uma espécie de caverna do Platão invertida). Segundo o filósofo, temos dificuldade de atribuir aos objetos da mente uma qualificação de reais, no mesmo nível que conferimos realidade à matéria, simplesmente porque eles não obedecem à regra que supomos comandar a realidade "exterior", a mesma que definimos anteriormente como critério de conhecimento: estar sujeito à predição. Como não podemos prever com facilidade o comportamento da mente, tendemos a negligenciar a "realidade auto-evidente do pensamento" (OSTWALD, 1907, p. 14). O que para o químico é um grande equívoco. A indeterminação e o livre-arbítrio, que se supõe no pensamento moderno como critério de diferenciação entre o espírito e a matéria, é criticado por ele como uma distinção ilusória. Segundo o autor, a História da Ciência está repleta de equívocos semelhantes, falsas dualidades, aparentes contradições que só existem enquanto miragem produzida pela deficiência de nossa linguagem. Tomando o termo emprestado de Ernest Mach (outro notório positivista), Ostwald nomeia essas miragens da linguagem como pseudoproblemas. De acordo com esta

\footnotetext{
${ }^{2} \mathrm{TN}=$ Tradução Nossa.
} 
definição, ele descreve a seguir o objetivo da Filosofia da Ciência (teoria do conhecimento ou epistemologia) como sendo o de separar os problemas reais (dignos de uma investigação científica) dos pseudoproblemas - para sempre insolúveis, pois não se referem a relações mensuráveis e não permitem predição. Como exemplos de pseudoproblemas, ele cita uma lista consideravelmente curiosa: a existência da matéria e dos átomos, o início do universo e a separação corpo-mente.

É neste ponto que Ostwald introduz sua Energética Moderna: uma visão de mundo com base científica, construída filosoficamente de modo a evitar os pseudoproblemas. $\mathrm{O}$ filósofo-cientista argumenta que à medida que a ciência foi investigando mais a fundo a realidade da matéria como substrato ontológico do real (ideia metafísica grega retomada na revolução mecanicista), não encontrou nada além de fantasmas. A suposta matéria (Ser) que deveria existir no vazio (não-ser) como suporte para as transformações do mundo, estava, ela própria, constantemente deixando de ser matéria e transformando-se em outra coisa. No estudo das reações químicas, em especial na combustão (onde Mayer e Helmholtz descobriram a lei de conservação da energia), somente partes ou as vezes nada da matéria inicial se conserva ao final do processo. Somente a energia, que é convertida em outros elementos como luz, calor e movimento. Assim, segundo Ostwald, a matéria foi aos poucos perdendo todos os seus direitos, sendo progressivamente substituída por um conceito mais abrangente e verdadeiramente científico: o da energia.

Diferente da matéria, todos os fenômenos podem ser descritos como transformações da energia, que é múltipla em suas formas, mas permanece sempre constante em todos os processos. Aqui o autor expõe sua principal tese: algo que pode ser descrito por uma grandeza numérica, que permanece sempre a mesma independente do processo, possui o mais alto grau de pretensão à realidade que uma coisa pode ter. Assim, numa inversão de valores, ele conecta numa única epistemologia, a postura instrumentalista do positivismo, com a pretensão à realidade da investigação filosófica profunda. É justamente por aplicar ao conhecimento científico o rigor e o critério exclusivamente instrumentalista do positivismo, que Ostwald chega à concepção da realidade da energia. Ou seja, é somente pelo fato da ciência só poder falar daquilo que ela mede, que é preciso agora afirmar a energia como Ser, no sentido ontológico tradicionalmente atribuído a Parmênides. A lei de conservação da energia, essencial para descrever qualquer reação química ou processo físico, aparece então como fundamento ontológico para unificar todas as ciências, pois oferece o substrato imóvel que é a medida total e invariável de toda mudança. Ou como Ostwald (1909 [grifo do autor] [TN]) descreve em seu discurso de recebimento do prêmio Nobel:

\footnotetext{
A suposição geral de coerência do mundo, que como nós sabemos forma a base de todas as ciências, provê os meios de investigar este mundo. Se essa coerência pode ser obtida universalmente é uma questão que não precisa ser respondida aqui, uma vez que só onde esta coerência pôde ser realmente encontrada é que se torna parte da Ciência. A existência dessa coerência, e portanto o problema mais geral da Ciência, pode ser expresso pela equação geral de função
}

$$
F(a, b, c, d \ldots)=0
$$


Ou seja, a coerência interna do mundo, aquilo que o torna acessível à razão humana e à ciência, deve-se ao fato de que todas as mudanças, todas as transformações, estão subordinadas umas às outras, de modo que o Todo permanece sempre o mesmo. Tratase de propor a energia como conceito fundamental da realidade, não mais apenas como uma grandeza abstrata presente nas teorias físico-químicas. Segundo o autor, é preciso agora pensar a energia enquanto substância no sentido aristotélico, isto é, como único objeto efetivamente real: "the thingishness or reality of energy" (OSTWALD, 1907, p. 6). A energia enquanto coisa em si, um objeto sem forma (pois forma todas as formas), indestrutível, eterno, incriado, mutável e imponderável. Poderíamos dizer, a energia como o Deus de Spinoza:

Os corpos com efeito não se distinguem entre si pela substância; por outro lado, o que constitui a forma de um indivíduo consiste em uma união de corpos. [...] Se alguns dos corpos que compõe um indivíduo forem forçados a desviar seu movimento de uma direção para outra, mas de tal maneira que possam continuar seus movimentos e transmiti-los entre si, na mesma proporção de antes, o indivíduo conservará sua mesma natureza, sem qualquer mudança de forma. [...] Se, agora, concebemos um outro indivíduo, composto de vários indivíduos de natureza diferente, veremos que também ele pode ser afetado de muitas outras maneiras, conservando, apesar disso, sua natureza. [...] E se continuarmos assim ao infinito, conceberemos facilmente que a natureza inteira é um Indivíduo, cujas partes, isto é, todos os corpos, variam de infinitas maneiras, sem nenhuma mutação do Indivíduo inteiro. (SPINOZA, 2013, p. 64-65).

Vemos em Spinoza, um autor do século XVII, a questão da energia ainda colocada como conservação do movimento, um jargão oriundo da ciência mecânica. Segundo Pinguelli Rosa (2005, p. 159-162), esta era a temática central nas discussões entre os cientistas de sua época. Um debate científico com teor teológico. Newton era contra o princípio de conservação do movimento, pois ele implicava um universo fechado em si mesmo e autossuficiente. O alquimista e filósofo natural inglês defendia a existência de um Deus criador transcendente, que num processo constante de criação, intervinha a cada instante no mundo. Por isso era preciso supor um universo aberto, eternamente alimentado de fora para manter-se em movimento. Leibniz é irônico quanto à essa posição, afirmando que o Deus de Newton havia criado um mundo tão imperfeito quanto um relógio mecânico, de tal modo que se Ele parasse de dar corda, o mundo inteiro pararia de girar:

Leibniz fala de um mundo em "movimento perpétuo", de um mundo em que causas e efeitos se geram uns aos outros perpetuamente, sem que jamais se possa dizer que o Universo recebeu uma força nova, isto é, que um corpo tenha adquirido força sem que outro a tenha perdido na mesma medida. Newton-Clarke falam da natureza como de um "trabalhador perpétuo", dizem-na tomada por um poder que a transcende, evocam forças de interação que não estão submetidas a uma lei de conservação, mas que traduzem a ação perpétua de Deus, autor atual de um mundo cuja atividade não cessa de sustentar. (PRIGOGINE \& STENGERS, 1992, p. 40)

Para Leibniz, o princípio de razão suficiente - a perfeita conexão reversível entre causa e efeito - garantiria a conservação da "força viva" (como ele chamava a energia do movimento), sem necessitar da intervenção milagrosa de um agente externo. A ciência 
parece por muito tempo confirmar a visão de Leibniz-Spinoza, encontrando uma profusão incontável de evidências a seu favor. Ela acabou por tornar-se a visão hegemônica daquilo que, paradoxalmente, convencionou-se chamar de física newtoniana. Mas há um problema filosófico mal resolvido por trás do princípio leibniziano: a questão do determinismo e o ideal de onisciência que ele pressupõe. Quando as pesquisas sobre o comportamento da energia longe do equilíbrio avançaram ao longo do século XX, um dos pilares da tradição física mostrou-se questionável:

\begin{abstract}
O princípio de razão suficiente implica que todo desvio em relação ao determinismo traduz uma definição incompleta do objeto, isto é, uma definição aberta à arbitrariedade. Porque se situava nesta tradição Einstein lutou contra toda forma de indeterminismo em física. Mas as noções de instabilidade e de acontecimento nada devem, como vimos, à arbitrariedade. Elas traduzem não a renúncia ao princípio de razão suficiente, e sim a descoberta de situações em que ele deixa de ser legítimo e entra em conflito com a própria noção de conhecimento cujo ideal é supostamente definido por ele. (PRIGOGINE \& STENGERS, 1992, p. 178)
\end{abstract}

\title{
3. Considerações Finais
}

Se a capacidade de previsão é a medida de nossa inteligência (OSTWALD, 1907, p. 13), então ao final de seu artigo Ostwald nos brinda com as maiores provas de sua genialidade, pois a História da Ciência é testemunha da veracidade de suas predições.

Primeiro, Ostwald (1907, p. 24 [TN]) menciona que: "Uma vez que nada de forma alguma no conceito geral de energia é dito sobre as relações de espaço e tempo, estas estão abertas para definições mais precisas". É bastante curiosa esta afirmação se considerarmos que ela foi escrita em 1907, justamente o período em que Albert Einstein desenvolvia sua revolucionária Teoria da Relatividade, onde não somente a massa aparece como equivalente à energia (denunciando mais uma vez a matéria como apenas uma das formas possíveis de energia), como também suas equações descreveriam como o ritmo do tempo e a geometria do espaço são determinados pela distribuição de energia. Com o avanço da física no século XX, o espaço que deveria ser vazio e estático para conter a matéria em movimento, revelou-se na verdade um oceano de energia em expansão acelerada, onde partículas de matéria nascem e morrem numa fração de segundo. Por outro lado, embora a teoria atômica tenha se mostrado bem sucedida, para desgosto dos positivistas (incluindo Ostwald), ainda assim o átomo se mostrou mais repleto de vazio do que propriamente constituído de coisas. Mesmo em seu núcleo duro, onde esperaríamos encontrar com mais clareza a tão sonhada partícula indivisível de matéria, os quantas mostraram-se furtivos e misteriosos. Os novos paradoxos e debates filosóficos levantados pelo problema da medida na mecânica quântica e a quebra do princípio de localidade, demonstram que os argumentos de Ostwald quanto à teoria atômica não perderam sua validade. Se ele tivesse participado dos desdobramentos epistemológicos que se seguiram na física atômica a partir de 1920, ele certamente teria repetido sua crítica, se tivesse sido convidado ao famoso encontro de Copenhague: do ponto de vista do Energetismo, a dualidade partícula/onda é mais um pseudoproblema, e 
não um paradoxo físico real. Sua solução é um exercício de filosofia da ciência, e não de física, e consiste simplesmente em colocar o problema sob uma perspectiva nãodualista, onde a partícula não existe por si mesma, mas é aquilo que aparece, ou não, dependendo do tipo de relação que se estabelece com a energia. Sendo a função de onda a descrição das relações possíveis ("o grau de liberdade"), o conjunto virtual de futuros possíveis de um dado sistema. É a suposição atomista de que as partículas existem por si mesmas que torna a função de onda misteriosa.

Por fim, em Ostwald (1907, p. 30), ele expõe o que acredita ser o problema mais importante do Energetismo e "o grande problema para o futuro da ciência": tendo alcançado grande rendimento na física e na química, a tarefa do Energetismo seria então lançar-se para o terreno da biologia e da psicologia. Se o ponto de vista da energia fosse capaz de explicar o alto grau de coerência nos fenômenos da vida e nos fenômenos da mente, então esta se firmaria definitivamente como a base transdisciplinar para conectar todas as ciências sob um mesmo paradigma. Tarefa necessária, segundo ele, pois "a grande unidade de todas as ciências decisivamente se destaca como princípio geral regulador." (OSTWALD, 1909). Ostwald termina seu texto afirmando que um avanço fundamental estava sendo realizado no terreno da psicologia pela ideia da existência de uma energia psíquica. Aqui ele se refere evidentemente às famosas pesquisas de psicofísica do médico-filósofo Wilhem Wundt, pioneiro em psicologia experimental e seu colega de trabalho na Universidade de Leipzig (STEWART, 2014, p. 4), mas também inegavelmente à psicanálise nascente, ao trabalho de Freud, Jung, Reich e de muitos outros que, ao longo do século XX, levaram adiante a concepção energética do mundo para tentar compreender os fenômenos da mente e do equilíbrio psíquico.

O próprio Ostwald não sabia, mas o avanço da termodinâmica nas décadas seguintes à sua aposentadoria, iria acabar por propor outro modelo de inteligibilidade para o mundo físico. A física estava prestes a descobrir a emergência do novo, a evolução do cosmos a partir de si mesmo e a imprevisibilidade dos sistemas complexos como qualidade intrínseca auto-emergente, onde as probabilidades se devem não somente à nossa ignorância em relação à cadeia infinita de causas, mas à definição mesma do universo enquanto um sistema dinâmico caótico, isto é, criativo e criador, onde tempo é invenção. O devir entra definitivamente no mundo físico com o desenvolvimento da cosmologia relativística, mas também a partir da termodinâmica dos sistemas instáveis, com o trabalho de outro químico ganhador do Nobel, Ilya Prigogine (1917 - 2003), que veio a mostrar como a lei da entropia pode estar relacionada ao aparecimento de estruturas auto-organizadas, onde padrões emergem espontaneamente em sistemas complexos, devido ao modo "criativo" como a energia se comporta longe do equilíbrio (PRIGOGINE \& STENGERS, 1992). Somente um universo com esta característica condiz com a constatação empírica da existência e evolução da vida e do cosmos como resultado de uma História particular. Nem um universo imutável fechado em si mesmo como o de Leibniz, Spinoza e Einstein, nem modificado por fora como o de Newton. O próprio Prigogine não hesitou em relacionar esta propriedade termodinâmica com a 
existência do tempo, a possibilidade da vida e da evolução cósmica, a criatividade da natureza e a mente humana. De um universo harmônico e cíclico regido por leis eternas e necessárias, saltamos para um cosmos caótico, criativo e em evolução. Mas seriam os dois modelos necessariamente excludentes? Ou seriam paradoxalmente complementares? Como conciliar de modo coerente a eternidade estável garantida na conservação da energia pela $1^{a}$ lei da termodinâmica, com a irreversibilidade da seta do tempo garantida pelo aumento de entropia na segunda $2^{a}$ a lei, que implica em evolução, história, memória e novidade no mundo físico? Parmênides e Heráclito mais uma vez. Ser ou devir? Destino ou invenção?

Ostwald (1907, p. 3) lamenta que, embora uma descoberta científica importante sempre cause revoluções na filosofia de sua época; infelizmente a ciência especializada é lenta para absorver os avanços filosóficos do seu tempo. Assim, paradoxalmente, a ciência está sempre tão atrás da filosofia quanto a filosofia está da ciência. Com a finalidade de ajudar a atenuar este quadro, acreditamos ter demostrado como as ideias apresentadas pelo químico-filósofo germânico em 1907, ainda são pertinentes para a ciência de hoje.

\section{Financiamento}

O presente trabalho foi realizado com apoio da Coordenação de Aperfeiçoamento de Pessoal de Nível Superior - Brasil (CAPES) - Código de Financiamento 001.

\section{Referências}

BENSAUDE-VINCENT, B. Revisiting the controversy on Energetics. In:Wilhelm Ostwald at the Crossroads Between Chemistry, Philosophy and Media Culture. Leipziger Universitätsverlag, 2005. p. 26.

OSTWALD, F. W. Nobel Lecture. 1909. NobelPrize.org. Nobel Media AB 2018. Sun. 9 Sep 2018. https://www.nobelprize.org/prizes/chemistry/1909/ostwald/lecture

. The monist. Rivista di Scienza, v. XVII, No 4. Out, 1907.

PEREIRA, L. S. Revisitando o legado de Wilhem Ostwald. Boletim Eletrônico da Sociedade Brasileira de História da Ciência, Boletim 14, 2017. Disponível em: https://www.sbhc.org.br/conteudo/view?ID_CONTEUDO=1011. Acesso: 06 jun 2020.

PINGUELLI ROSA, L. Tecnociências e Humanidades: novos paradigmas, velhas questões - Volume 1: o determinismo newtoniano na visão de mundo moderna. São Paulo: Editora Paz e Terra, 2005.

PRIGOGINE, I.; STENGERS, I. Entre o tempo e a eternidade. São Paulo: Companhia das Letras, 1992. 
SPINOZA, B. Ética. Belo Horizonte: Autêntica Editora, 2013.

STEWART, J. Sociology, Culture and Energy: The Case of Wilhelm Ostwald's 'Sociological. Cultural Sociology, 2014. 